\title{
Hubungan Budaya Kerja dan Koordinasi Terhadap Kinerja Organisasi pada Badan Pengembangan Sumber Daya Manusia (BPSDM) Provinsi Jambi
}

\author{
Enadarlita, Musfarita Affiani \\ Widyaiswara BPSDM Provinsi Jambi \\ Correspondence email: enadarlita@yahoo.com, yeyen.gr@gmail.com
}

\begin{abstract}
This study aims to analyze the magnitude of the relationship 1) work culture towards organizational performance in BPSDM Jambi Province. 2) Coordination of organizational performance in BPSDM Jambi Province. 3) Work culture and Coordination of organizational performance in BPSDM Jambi Province. This study uses quantitative methods with the type of survey approach. Data collection techniques are carried out by interviews, observations, questionnaires, and documentation. Based on the results of data analysis, the conclusions that can be drawn from this study are 1) Work culture (X1) has an influence on organizational performance because the significance value is 0.041 $<0.05$ and $t$ count $>t$ table (2.064> 1.66), meaning HO is rejected and Ha is accepted. 2) Coordination (X2) does not have an influence on organizational performance because the value of Significance is 0.109>0.05 and seen from the value of $t$ count <t table $(1.615<1.66)$, means $\mathrm{HO}$ is accepted and Ha is rejected or coordination does not have a significant effect on organizational performance. 3) Based on F count 3.091> F table (2.92) and significance $0.049<0.05 \%$ means Ho is rejected and $\mathrm{Ha}$ is accepted or work culture and coordination simultaneously have an influence on organizational performance. So the conclusion is that if the work culture and coordination are carried out together well, then the organization's performance will also increase and vice versa.
\end{abstract}

Keywords: Work culture, Coordination, Organizational Performance

\section{PENDAHULUAN}

Manusia merupakan sumber daya paling strategik yang dimiliki oleh suatu organisasi, tanpa mengurangi pentingnya sumber daya yang lain seperti modal, mesin, waktu, energi, informasi dan sebagainya. Walaupun dana dan daya memungkinkan organisasi berbuat sesuatu, akan tetapi sumber daya manusia yang menyebabkan berlangsungnya suatu organisasi. Dalam sebuah organisasi pemerintah, Pegawai merupakan penggerak utama dalam segala kegiatan organisasi. Keberhasilan suatu organisasi sangat dipengaruhi oleh kinerja pegawainya. Hal ini sebagaimana diatur dalam Undang-undang Nomor 5 Tahun 2014 tentang Aparatur Sipil Negara. Selain itu juga menyiratkan amanat bahwa dalam rangka usaha mencapai tujuan nasional diperlukan pegawai negeri sipil yang berperan sebagai pelayan masyarakat, dengan penuh kesetiaan kepada Pancasila dan Undang-undang Dasar 1945. Untuk menjalankan itu semua dituntut PNS yang kompeten dibidangnya. Namun kenyataannya pelaksanaan tugas aparatur sipil negara belum berjalan sebagaimana yang diamanatkan oleh undang-undang tersebut, hal ini tentu dipengaruhi oleh banyak faktor seperti kompetensi aparatur, lingkungan kerja, budaya yang beragam, masih lemahnya koordinasi.

Menurut Sedarmayanti (2017), lingkungan kerja adalah keseluruhan alat perkakas dan bahan yang dihadapi, lingkungan sekitar dimana seseorang bekerja, metode kerja, serta pengaturan kerja baik sebagai perseorangan maupun sebagai kelompok. Dengan demikian dapat ditarik sebuah kesimpulannya bahwa kondisi lingkungan kerja yang baik akan menunjang produktivitas karyawan yang pada akhirnya berdampak pada meningkatnya kinerja pegawai. Kondisi lingkungan kerja dapat dikatakan baik atau sesuai apabila sumber daya manusia dalam suatu organisasi dapat melaksanakan kegiatannya secara optimal, sehat, aman dan nyaman. Ketidaksesuaian suatu lingkungan kerja dapat dilihat akibatnya dalam jangka waktu yang cukup lama. Lebih jauh lagi, keadaan lingkungan kerja yang kurang baik dapat mengakibatkan penggunaan tenaga dan waktu yang lebih banyak serta tidak mendukung diperolehnya suatu rancangan sistem kerja yang efisien.

Wibowo (2013) mengatakan setiap organisasi berkeinginan mencapai tingkat kinerja tinggi. Untuk itu perlu mengetahui perkembangan pecapaian standar, target dan waktu yang tersedia.Pengukuran perlu dilakukan untuk mengetahui apakah pelaksanaan dapat berjalan sesuai rencana, apakah terdapat kesenjangan kinerja dan 
apakah hasil akhir dapat dicapai. Kinerja organisasi mempunyai banyak pengertian. Kinerja organisasi adalah sebagai efektivitas organisasi secara menyeluruh untuk kebutuhan yang ditetapkan dari sekelompok yang berkenaan melalui usaha-usaha yang sistemik dan meningkatkan kemampuan organisasi secara terus menerus untuk mencapai kebutuhannya secara efektif. Veithzal, et.all (2014) mengatakan hasil penilaian kinerja dapat menunjukkan apakah SDM telah memenuhi tuntutan yang dikehendaki oleh organisasi. Baik dilihat dari ssis kualitas maupun kuantitas . Informasi dari penilaian kinerja karyawan merupakan refleksi dari berkembang atau tidaknya perusahaan/organisasi. Menurut Veithzal (2014) performance is defined as the record of outcome produced on a specified job function or activity during time period. Menurut Sedarmayanti (2017) Penilaian prestasi kerja merupakan hasil kerja pegawai dalam lingkup tanggung jawabnya.

Dalam pelayanan terdapat indikator kinerja pelayanan, dimana menurut LAN-RI (1999) adalah ukuran kuantitatif dan kualitatif yang menggambarkan tingkat pencapaian suatu sasaran atau tujuan yang telah ditetapkan dengan mempertimbangkan indikator masukan (inputs) yaitu segala sesuatu yang dibutuhkan agar pelaksanaan kegiatan dapat berjalan untuk menghasilkan keluaran antara lain: dana, SDM, informasi, kebijakan, atau regulasi, keluaran (outputs) yaitu sesuatu yang dicapai dari suatu kegiatan dapat berupa fisik atau non fisik, hasil (outcomes) yaitu: segala sesuatu yang mencerminkan berfungsinya keluaran kegiatan pada jangka menengah(efek langsung), manfaat (benefits) yaitu sesuatu yang terkait dengan tujuan akhir dari pelaksanaan kegiatan. dan indikator dampak (impacs)yaitu pengaruh yang ditimbulkan baik positif maupun negatif pada setiap tingkatan indikator berdasarkan asumsi yang telah ditetapkan.

Budaya kerja merupakan suatu pemahaman, sikap dan perilaku yang diterapkan orang-orang sewaktu melaksanakan pekerjaan dalam suatu organisasi/institusi. Nilai yang dianut dalam menerapkan budaya kerja sewaktu bekerja dapat menentukan kualitas suatu pekerjaan yang dilakukan seseorang atau sekelompok orang. Apabila para pegawai yang bekerja dalam suatu institusi mampu menerapkan budaya kerja berkualitas tentu dapat pula meningkatkan kualitas pelayanan publik dari pada pemerintah maupun pemerintah daerah. Terdapat sejumlah budaya kerja yang bernilai negatif masih menghiasi pelaksanaan tugas dan kewajiban oleh para pegawai berpotensi menghambat kinerja organisasi. Mutu sumberdaya manusia Indonesia yang tidak mampu bersaing, hal ini disebabkan oleh karena faktor budaya kerja yang juga masih lemah dan tidak merata. Ada anggapan bahwa budaya kerja produktif di Indonesia, belum merata karena bekerja masih dianggap sebagai sesuatu yang rutin, dalam hal suatu instansi mempunyai budaya kerja positif yang kuat dalam bekerja, terjadi sinergisitas antara pegawai staf dengan pimpinannya, maka para pimpinan tidak tersita waktu, pemikiran dan tenaga hanya untuk menyelesaikan konflik diantara mereka karena perbedaan nilai budaya yang dianut dalam bekerja. Dengan demikian pelayanan publik yang dilakukan dalam instansi tersebut akan dapat menjadi berkualitas dan prima dalam memberikan layanan kepada masyarakat. Suatu pelayanan publik yang berintegritas adalah suatu pelayanan yang dilakukan dengan sepenuh hati berdasarkan karakter moral dan etika yang benar. Hal ini dimakusdkan agar pelayanan yang diberikan menghasilkan suatu kebaikan bagi masyarakat pengguna jasa layanan publik tersebut. Apabila pelayanan seperti ini dilaksanakan oleh instansi pemerintahan ataupun pemerintah daerah akan dapat membangun kepercayaan masyarakat kepada pemerintah ataupun pemerintah daerah tersebut. Namun mungkin penerapan budaya kerja berkualitas ini masih lemah dan tidak merata. Sehingga muncul anggapan bahwa budaya kerja aparatur sipil negara termasuk pegawai negeri sipil (PNS) di dalamnya kurang memahami budaya kerja positif. Ini terlihat dengan adanya anggapan bahwa para PNS bekerja masih dianggap sebagai sesuatu yang rutin. Bahkan di sebagian PNS, bisa jadi bekerja dianggap sebagai beban dan paksaan terutama bagi orang yang malas. Apabila alat ukur yang tepat dalam mengkategori budaya kerja yang berkualitas belum ditentukan, maka akan terlihat sebagian pimpinan dalam berbagai instansi pemerintah daerah memberi tugas kepada pegawai di lingkungan instansinya tanpa melihat kemampuan yang dimiliki. Yang dipentingkan adalah asal itu bisa membuat posisi sang pimpinan aman dan terkendali. Keadaan ini juga dapat kemungkinannya disebabkan ketidakmampuan pemerintah daerah untuk melakukan perubahan struktur, norma, nilai bagi pegawai di daerah, telah menyebabkan gagalnya upaya untuk memenuhi aspirasi dan kebutuhan masyarakat. Sehingga muncul anggapan masyarakat bahwa kualitas dan kinerja birokrasi dalam 
memberikan pelayanan publik masih jauh dari harapan. Masih belum tercipta budaya pelayanan publik yang berorientasi pada kebutuhan pelanggan (service delivery culture). Sebaliknya, yang terbentuk adalah obsesi para birokrat dan politisi untuk mengalihkan birokrasi sebagai lahan pemerintahan hasrat dan kekuasaan (power culture).

Hasil penelitian Shinta (2014) bahwa belum ada solusi yang dapat memecahkan sebab akibat penurunan kualitas pelayanan Publik. Seiring dengan hal itu, masyarakat semakin menuntut efektivitas kerja Pelayanan aparatur pemerintah sebagai abdi Negara. Image tentang rendahnya kinerja sektor publik tentu sudah tidak asing lagi. Selain kinerja yang rendah, diwarnai juga birokrasi yang sulit, berbelit-belit dan intrik praktik suap yang selalu mewarnai dan menjadikan citra aparatur di sektor publik semakin buruk. Untuk itulah kedepan budaya organisasi yang tidak kondusif harus dirubah menjadi organisasi yang berkinerja tinggi dan terukur dalam memberikan pelayanan kepada masyarakat. Lemahnya budaya organisasi pada kebanyak sektor publik atau pada kebanyakan organisasi pemerintah menurut Dewi Sartika (dalam LAN-RI; 2004) disebabkan antara lain oleh faktor: (a) Aparat pemerintah kebanyak berorientasi pada peraturan, bukan pada visi dan misi organisasinya; (b) Ketidak jelasan visi dan misi organisasi; (c) Sistem kompensasi yang kurang layak dan kuran adil; (d) Lebih melayani atasan daripada melayani masyarakat; (e) Promosi yang didasari senioritas daripada kompetensi; (f) Membudayanya korupsi, kolusi dan nepotisme di lingkungan kerja.

Upaya untuk merubah aparatur dari budaya organisasi semacam itu sebenarnya sudah dilakukan dengan menerapkan program budaya kerja aparatur, dengan maksud meningkatkan produktivitas kerjanya. Namun memang dirasakan belum bisa optimal. Bertitik tolak dari hal tersebut, maka dalam mewujudkan organisasi berkinerja tinggi dari aspek Rastogi, suatu nilai-nilai budaya kerja yang mampu mengarahkan bagi mereka boleh bekerja secara bermutu dan produktif. Budaya kerja yang produktif mempunyai nilai-nilai yaitu: (a) Suatu kemampuan seseorang untuk senantiasa mempunyai prestasi kerja peringkat tinggi, merasa bangga atas keunggulan, dan kesediaan untuk belajar dan melampaui prestasi kerja; (b) Menyakini peningkatan kualitas mutu dari produktifitasnya dapat meningkat pula kesejahteraan diri dan kemajuan organisasi; dan (c) suatu orientasi yang tinggi dengan sikap kooperatif dalam hubungan antara pribadi, rela dan tulus hati dalam prestasi kerja dengan mendasarkan kepercayaan timbal balik, rasa hormat dan membahagi bersama pengenalan dengan organisasi.

Atribut dari budaya kerja ini dapat dipergunakan sebagai penanda dalam rangka membantu para aparatur untuk menjadi amanah dalam melayani kepentingan masyarakat sebagai bentuk upaya semangat untuk selalu berjuang menggapai prestasi yang tinggi. Dengan demikian dapat dikatakan bahwa tujuan budaya kerja itu adalah (a) meningkatkan kualitas hasil kerja; (b) meningkatkan kualitas pelayanan; (c) menciptakan budaya kualitas; (d) budaya, diperlukan komitmen tinggi dan meningkatkan profesionalitas; (e) mengurangi konsensus bersama sebagai hal penting yang menjadi prasyarat untuk mewujudkan organisasi yang berkinerja tinggi. Sehubungan dengan latar belakang diatas maka peneliti bermaksud meneliti tentang Pengaruh Budaya Kerja PNS terhadap Kinerja Pegawai Badan Pengembangan Sumber Daya Manusia Provinsi Jambi. Koordinasi berasal dari kata coordination, co dan ordinare yang berarti to regulate. Dari pendekatan empirik yang dikaitkan dengan etimologi, koordinasi diartikan sebagai kegiatan yang dilakukan oleh berbagai pihak yang sederajat (equal in rank or order, of the same rank or order, not subordinate) untuk saling memberi informasi dan mengatur (menyepakati) hal tertentu (Ndraha, 2010). Koordinasi sangat berperan signifikan dalam menciptakan efektivitas organisasi. Koordinasi adalah kegiatan menyatukan, mengarahkan, dan mengkoordinasikan unsurunsur manajemen dan pekerjaan-pekerjaan para karyawan dalam mencapai tujuan organisasi. Menurut Ismail (2009), karateristik pertama dari organisasi adalah adanya koordinasi upaya dari sumber daya manusia yang terlibat dalam organisasi. (Adisetiawan, 2014)

Menurut Veithzal dkk (2014) koordinasi merupakan aktivitas membawa orang-orang, materiil, pikiranpikiran, teknik-teknik dan tujuan-tujuan kedalam hubungan yang harmonis dan produktif dalam mencapai tujuan. Sesuai dengan pendapat para pakar tersebut dapat disintesakan bahwa koordinasi merupakan penggabungan dari unsur-unsur manajemen mulai dari planning, organizing, actuating dan controlling (POAC) 
baik secara vertikal maupun horizontal sehingga terbentuknya kerjasama/kolaborasi. Koordinasi dapat dilakukan melalui pendelegasian wewenang yang tepat, pembagian kerja yang jelas, serta adanya komunikasi yang baik antar anggota organisasi. Koordinasi merupakan suatu hal yang sangat penting di dalam suatu organisasi. Dalam mencapai tujuannya, jika para pimpinan organisasi tidak dapat menerapkan koordinasi yang baik maka akan terjadi kekacauan, perselisihan dan kekembaran pekerjaan atau kekosongan pekerjaan sehingga efektivitas organisasi tidak tercapai. (Adisetiawan, 2013)

\section{METODE PENELITIAN}

Populasi adalah jumlah dari keseluruhan objek (satuan-satuan atau individu-individu) yang karakteristiknya diduga. Populasi penelitian ini adalah seluruh PNS yang berada di BPSDM Provinsi Jambi. Sampel adalah bagian dari populasi yang menjadi sumber data (Hadi, 2011).Menurut Sugiono (2012) sampel adalah sebagian dari jumlah dan karakteristik yang dimiliki oleh populasi tersebut. Sampel dalam penelitian ini adalah Pegawai Negeri Sipil yang bertugas di Badan Pengembangan Sumber Daya Manusia (BPSDMP Provinsi Jambi. Menurut Mukhtar (2013) ukuran minimum sampel yang dapat diterima sebaiknya didasarkan pada desain atau metode penelitian yang digunakan, dimana populasi yang dipandang relatif homogen, maka populasi dapat ditarik minimal $5 \%$ dan maksimal 30\%, dan apabila jumlah populasi sekitar 150 orang maka jumlah sampel sama dengan jumlah populasi. Mengingat jumlah PNS yang ada di BPSDM Provinsi jambi berjumlah $<150$ orang maka sesuai dengan pendapat Gay sampel penelitian ini sama dengan jumlah populasi yaitu 112 orang.

\section{HASIL DAN PEMBAHASAN}

\section{Tabel 1}

\section{Nilai Koefisiensi Determinasi Regresi}

\begin{tabular}{|l|r|r|r|r|r|}
\hline Model & R & R Square & Adjusted R Square & Std. Error of the Estimate \\
\hline 1 &, $232^{\mathrm{a}}$ &, 054 &, 036 & 12,242 \\
\hline
\end{tabular}

Sumber: data olahan

Berdasarkan tabel diatas dapat dilihat bahwa nilai koefisiensi determinasi adjusted $\mathrm{R}$ Square adalah sebesar 0,036 atau $(0,36 \%)$. Hal ini berarti bahwa budaya kerja dan koodinasi dalam menjelaskan hubungan terhadap kinerja organisasi adalah sebesar 0,36\% sedangkan sisanya 96,4\% di pengaruhi faktor lain diluar itu.

Tabel 2

Uji Parsial (Uji t)

\begin{tabular}{|c|c|c|c|c|c|c|}
\hline \multirow{2}{*}{\multicolumn{2}{|c|}{ Model }} & \multicolumn{2}{|c|}{ Unstandardized Coefficients } & Standardized Coefficients & \multirow{2}{*}{$\mathrm{t}$} & \multirow{2}{*}{ Sig. } \\
\hline & & $\mathrm{B}$ & Std. Error & Beta & & \\
\hline \multirow{3}{*}{1} & (Constant) & 33,757 & 19,546 & & 1,727 & ,087 \\
\hline & Budaya kerja $\mathrm{X} 1$ &, 325 & 157 & ,194 & 2,064 & 041 \\
\hline & Koordinasi_X2 & 229 & , 142 & 151 & 1,615 & 109 \\
\hline
\end{tabular}

Sumber: data olahan

Berdasarkan tabel diatas dapat dilihat sebagai berikut:

- Pengujian Hipotesis budaya kerja $\left(X_{1}\right), t$ hitung budaya kerja $\left(X_{1}\right)=2,064$ dengan Signifikan $=0,041, t$ tabel $=1$,66. Jadi $t$ hitung $>\mathrm{t}$ tabel $(2,064>1,66)$, berarti $\mathrm{H}_{0}$ ditolak dan $\mathrm{H}_{\mathrm{a}}$ diterima atau budaya kerja $\left(\mathrm{X}_{1}\right)$ mempunyai pengaruh terhadap kinerja organisasi (Y), dan dapat juga dilihat dari level Signifikan $0,041<$ 0,05 (alpha) berarti koordinasi $\left(\mathrm{X}_{1}\right)$ mempunyai pengaruh signifikan terhadap kinerja organisasi (Y). Jadi kesimpulannya adalah jika budaya kerja yang dilakukan PNS baik maka kinerja organisasi juga akan tinggi dan begitu juga sebaliknya. 


\section{Enadarlita, Musfarita Affiani}

- $\quad$ Pengujian Hipotesis koordinasi $\left(X_{2}\right)$ : $t$ hitung koordinasi $\left(X_{2}\right)=1,615$ dengan $\operatorname{Sig}=0,109 \mathrm{t}$ tabel = 1,66; $\mathrm{t}$ hitung $<\mathrm{t}$ tabel $(1,280<1,66)$, bertarti $\mathrm{H}_{0}$ diterima dan Ha ditolak atau koordinasi $\left(\mathrm{X}_{2}\right)$ tidak mempunyai pengaruh terhadap efektivitas organisasi (Y); dan dapat juga dilihat dari level Sign 0,109 > 0,05 (alpha) berarti koordinasi $\left(\mathrm{X}_{2}\right)$ tidak mempunyai pengaruh signifikan terhadap efektivitas organisasi (Y). Jadi kesimpulannya adalah meskipun koordinasi seorang PNS baik, belum tentu dapat meningkatkan kinerja organisasi begitu juga sebaliknya.

\section{Analisis F Value}

$\mathrm{F}$ value atau uji $\mathrm{F}$ dilakukan untuk mengetahui apakah semua variabel independen yang dimasukan dalam model, memiliki hubungan secara bersama-sama (simultan) terhadap variabel dependen. Tabel Annova, khususnya pada kolom $\mathrm{F}$ dan Signifikan dibawah ini berfungsi untuk menjawab tujuan penelitian, yaitu hubungan secara simultan.

Tabel 3

Anova

\begin{tabular}{|ll|r|r|r|r|r|}
\hline & Model & Sum of Squares & \multicolumn{1}{|c|}{ df } & Mean Squre & \multicolumn{1}{c|}{ F } & \multicolumn{1}{c|}{ Sign } \\
\hline 1 & Regression & 926,446 & 2 & 463,223 & 3,091 &, $049^{\mathrm{b}}$ \\
& Residual & 16335,554 & 109 & 149,867 & & \\
Total & 17262,000 & 111 & & & \\
\hline
\end{tabular}

Sumber: data oalahn

Pengujian Hipotesis ketiga terdapat hubungan budaya kerja $\left(\mathrm{X}_{1}\right)$, dan koordinasi $\left(\mathrm{X}_{2}\right)$, terhadap kinerja organisasi (Y) secara simultan

- $\mathrm{H}_{0}=$ budaya kerja $\left(\mathrm{X}_{1}\right)$, koordinasi $\left(\mathrm{X}_{2}\right)$, tidak mempunyai hubungan signifikan terhadap kinerja organisasi (Y) secara Simultan

- $\quad \mathrm{H}_{\mathrm{a}}=$ budaya kerja $\left(\mathrm{X}_{1}\right)$, dan koordinasi $\left(\mathrm{X}_{2}\right)$, mempunyai hubungan signifikan terhadap kinerja organisasi (Y) secara Simultan

Pembahasan Pengujian Hipotesis ketiga :

- $\quad$ F hitung $=3,091$ dan level sign.(alpha) $=0,049$

- $\quad$ F Table $=2,92$

- $\quad$ Jika $\mathrm{F}$ hitung > F table $(3,091>2,92)$, berarti $\mathrm{H}_{\mathrm{o}}$ di tolak dan $\mathrm{H}_{\mathrm{a}}$ di terima atau budaya kerja $\left(\mathrm{X}_{1}\right)$, dan koordinasi $\left(\mathrm{X}_{2}\right)$, secara simultan mempunyai hubungan dengan kinerja organisasi (Y). dan dapat juga dilihat dari level Signifikan $0.049<0.05$ berarti budaya kerja $\left(\mathrm{X}_{1}\right)$, koordinasi $\left(\mathrm{X}_{2}\right)$, secara bersama-sama mempunyai hubungan signifikan terhadap kinerja organisasi (Y). Jadi kesimpulannya adalah jika budaya kerja dan koordinasi secara bersama-sama baik, maka kinerja organisasi juga akan baik dan begitu juga sebaliknya.

Analisis regresi linier bertujuan untuk menguji pengaruh variabel budaya kerja, koordinasi, terhadap kinerja organisasi. Jadi dapat disimpulkan bahwa persamaan regresi yang dihasilkan:

Masukan data Unstandardizied Coeficients

$\mathrm{Y}=33,757+0,325 \mathrm{X}_{1}+0,229 \mathrm{X}_{2}+\mathrm{e}$

- Nilai konstanta menunjukkan pengaruh variabel $X\left(X_{1}\right.$, dan $\left.X_{2}\right)$, bila variabel $X$ naik satu satuan maka variabel Y juga akan naik sebesar satu satuan. Artinya variabel kinerja organisasi (Y) akan naik atau terpenuhi sebesar satu-satuan jika $\mathrm{X}_{1}$, dan $\mathrm{X}_{2}$.

- Nilai koefisien regresi variabel budaya kerja_X $X_{1}$ dengan variabel Kinerja Organisasi (Y) adalah sebesar 0,325 artinya jika budaya kerja_X1 mengalami peningkatan 1 satuan, maka kinerja organisasi_Y akan mengalami peningkatan sebesar konstanta $=33,757$. Koefisien bernilai positif artinya antara budaya kerja_X1 dan kinerja organisasi_Y mempunyai hubungan yang positif. 
- Nilai koefisien regresi variabel koordinasi_X2 dengan variabel kinerja organisasi_Y adalah sebesar 0,229 artinya jika koordinasi_X2 mengalami kenaikan 1 satuan, maka kinerja organisasi_Y akan mengalami peningkatan sebesar konstanta $=33,757$. Koefisien bernilai positif artinya antara koordinasi_ $\mathrm{X}_{2}$ dan kinerja organisasi_Y mempunyai hubungan yang positif

\section{SIMPULAN}

Merujuk pada hasil penelitian maka dapat disimpulkan bahwa budaya kerja dan koordinasi dilakukan secara bersama-sama dengan baik, maka kinerja organisasi juga akan meningkat dan begitu juga sebaliknya.

\section{DAFTAR PUSTAKA}

Adisetiawan, R., 2014, Performance Mahasiswa Fakultas Ekonomi Universitas Batanghari, Jurnal Ilmiah Universitas Batanghari Jambi, 14(3), 1-10

Adisetiawan, R., 2013, Kajian Persepsi Pemilik Usaha Kecil dan Menengah (UKM) Terhadap Laporan Keuangan, Jurnal Ilmiah Universitas Batanghari Jambi, 13(4), 162-173

Ismail, Hanif dan Darsono Prawironegoro. 2009,Sistem Pengendalian Manajemen Konsep dan Aplikasi, Jakarta. Mitra Wacana Media

Mukhtar. 2013. Metode praktis penelitian deskriptif kualitatif, Jakarta; Referensi

Ndraha. Budaya Organisasi. PT. Rineke Cipta Jakarta. 2010.

Peraturan Pemerintah Republik Indonesia Nomor 11 Tahun 2017, Tentang Manajemen Pegawai Negeri Sipil. Undang-undang nomor 5 tahun 2014 tentang Aparatur Sipil Negara

Sedarmayanti, 2017, Perencanaan dan pengembangan sumber daya manusia. Untuk meningkatkan kompetensi, kinerja dan produktifitas kerja Bandung: Refika Aditama, Cetakan ke Satu

Sugiono, 2012, Metode Penelitian Administrasi, Bandung : Alfabeta

Sutrisno Hadi, 2011, Statistik, Yogyakarta:Andi

Veithzal, et.all. 2014. Kepemimpinan dan Perilaku Organisasi. Edisi Keempat. PT. Raja Grafindo Perkasa, Jakarta

Wibowo. 2013. Manajemen Kinerja. Cetakan ke 7, Jakarta Raja Grafindo Persada 